\title{
An update in the treatment preference for hyperthyroidism
}

Obin Kwon (D)

I read with pleasure the Review titled "Global epidemiology of hyperthyroidism and hypothyroidism" by Peter Taylor and colleagues (Global epidemiology of hyperthyroidism and hypothyroidism. Nat. Rev. Endocrinol. 14, 301-316 (2018)) ${ }^{1}$.

In this paper, the authors review the global situation of thyroid dysfunction and the effect of environmental factors, including iodine nutrition. I laud the authors' efforts to enhance the global understanding of thyroid health, especially for developing countries, by reviewing cumulative reports; however, I would like to make a comment Xabout references that are out of date.

The authors state that $10 \%$ of practitioners recommended thyroidectomy as the first-line treatment for Graves disease in South Korea. This comment cited a figure from a 2008 report by Bijay Vaidya et $\mathrm{al}^{2}{ }^{2}$, which included the data of preferred treatment modalities for Graves disease across the European Thyroid Association (ETA) and the American
Thyroid Association (ATA), as well as other national surveys. Korean data in this report were based on data from another survey in East Asian countries that was published in $1997\left(\right.$ REF. $\left.^{3}\right)$, which again quoted a previous study conducted in South Korea that was published in 1992 (REF. ${ }^{4}$ ). In this original survey, responses to the questionnaire from 64 Korean Thyroid Association (KTA) respondents were analysed and $8 \%$ of responders preferred thyroidectomy as first-line treatment for Graves disease in the index case (a 43-year-old woman with moderate but overt signs and symptoms of hyperthyroidism for 2-3 months). The authors commented on the high proportion of surgical treatments due to the relatively large number of surgeons (22\%) among respondents ${ }^{4}$.

However, in the recent consensus report of the KTA in 2013, 97.1\% of KTA members reported choosing antithyroid drugs and the remaining $2.9 \%$ chose radioactive iodine for the initial treatment of Graves disease in the same index case ${ }^{5}$. As thyroidectomy is rarely chosen as the first-line treatment for Graves disease in Korea, this comment by Taylor et al., which is based on outdated data, needs to be revised.

Again, I do appreciate the authors' efforts to increase awareness of the global variation for the prevalence and treatment of thyroid dysfunction. Nevertheless, referring to more recent, original data would help prevent confusion and promote more accurate understanding.

Obin Kwon iD

Department of Psychiatry, Harvard Medical School and Molecular Neurobiology Laboratory, McLean Hospital, Belmont, MA, USA. e-mail:okwon@mclean.harvard.edu https://doi.org/10.1038/s41574-018-0023-3

1. Taylor, P. N. et al. Global epidemiology of hyperthyroidism and hypothyroidism. Nat. Rev. Endocrinol. 14, 301-316 (2018).

2. Vaidya, B., Williams, G. R., Abraham, P. \& Pearce, S. H. Radioiodine treatment for benign thyroid disorders: results of a nationwide survey of UK endocrinologists. Clin. Endocrinol. 68, 814-820 (2008).

3. Tominaga, T. et al. International differences in approaches to ${ }^{131}$ I therapy for Graves' disease: case selection and restrictions recommended to patients in Japan, Korea, and China. Thyroid 7, 217-220 (1997)

4. Cho, B. Y. \& Koh, C. S. Current trends in the diagnosis and treatment of Graves' disease in Korea. J. Kor. Soc Endocrinol. 7, 216-227 (1992).

5. Moon, J. H. \& Yi, K. H. The diagnosis and management of hyperthyroidism in Korea: consensus report of the Korean Thyroid Association. Endocrinol. Metab. 28, 275-279 (2013).

Competing interests

The author declares no competing interests. 